\title{
Influence of socioeconomic status on changes in body size and physical activity in ageing black South African women
}

\author{
Philippe Jean-Luc Gradidge ${ }^{1 *}$, Shane A. Norris ${ }^{2}$, Richard Munthali and Nigel J. Crowther ${ }^{3}$
}

\begin{abstract}
Background: The increasing prevalence of obesity in sub-Saharan African women is not well understood, and black South African women in the region are particularly vulnerable. This study aimed to examine whether the relationship of socioeconomic status (SES) with changes in body mass index (BMI) and waist circumference (WC) is mediated by physical activity in ageing African women.

Methods: In a longitudinal analysis of the 518 caregivers associated with the Birth to Twenty Plus study, the role of SES associated with 10-year changes in BMI and WC was tested using structural equation modelling (SEM). The degree of mediation of moderate-vigorous physical activity (MVPA) and sitting time in this association was also assessed.

Results: The prevalence of obesity increased significantly from baseline to follow-up $(p<0.0001)$. In the SEM models, baseline SES had a direct positive effect on changes in $\mathrm{BMI}(\beta, 95 \% \mathrm{Cl}, 0.02$ ( 0.005 to 0.04$)$, and a direct negative effect on changes in MVPA $(\beta, 95 \% \mathrm{Cl},-3.81$ ( -6.92 to -0.70$)$. Baseline MVPA had a direct negative effect $(\beta, 95 \% \mathrm{Cl},-0.002$ (- 0.003 to -0.0003$)$ and indirect positive effect via change in MVPA ( $\beta, 95 \% \mathrm{Cl}, 0.01$ (0.0001 to 0.001) on change in WC.
\end{abstract}

Conclusions: Our study demonstrates the role and interaction of sociodemographic and behavioural predictors of obesity, and suggests a multifaceted approach to management of the crisis in communities of ageing urban African women.

Keywords: Body mass index, Waist circumference, Socioeconomic status, Physical activity, Sitting time, Urban, African women

\section{Background}

Obesity is multifaceted and complex, driven largely by factors associated with obesogenic urban environments [1]. Within these settings, the poor seem to have a greater burden of obesitycompared with the more affluent [2]. Recent evidence demonstrates that the prevalence of obesity has doubled since 1980 and currently affects more than 604 million adults globally [3]. These data indicate a trend for obesity to continue increasing, especially in women living in low- and middle-income countries. The estimates of obesity are higher in north

\footnotetext{
* Correspondence: philippe.gradidge@wits.ac.za

${ }^{1}$ Centre for Exercise Science and Sports Medicine, Faculty of Health Sciences,

University of the Witwatersrand, Johannesburg, South Africa

Full list of author information is available at the end of the article
}

and southern Africa than the global prevalence of obesity [4], with a recent study demonstrating that the increase in severe obesity from 1975 to 2014 in South African women was higher than those of more affluent countries such as France and the United Kingdom [5]. These trends in obesity are worrying for African populations, particularly as obesity increases the risk of associated non-communicable chronic diseases and certain types of cancers [6], in addition to lowering life expectancy by increasing the risk of early mortality [7]. Being obese is also associated with lower health-related quality of life and functionality, and is especially important in the context of an increasing ageing population with excess fat accumulation [8].

(C) The Author(s). 2018 Open Access This article is distributed under the terms of the Creative Commons Attribution 4.0 International License (http://creativecommons.org/licenses/by/4.0/), which permits unrestricted use, distribution, and reproduction in any medium, provided you give appropriate credit to the original author(s) and the source, provide a link to the Creative Commons license, and indicate if changes were made. The Creative Commons Public Domain Dedication waiver (http://creativecommons.org/publicdomain/zero/1.0/) applies to the data made available in this article, unless otherwise stated. 
In the sub-Saharan African region, it is black South African women who are the most vulnerable to overweight and obesity [9]. The underlying causes of the excess fat accumulation, particularly in the visceral region of ageing women are uncertain, however an increased risk of cardiometabolic diseases has been observed [10], in addition to an associated lower physical activity energy expenditure in older subjects compared with younger subjects [11]. In the South African setting where disparities are still evident, socioeconomic status (SES) may also have a role in the weight gain of African women. Data show that black South African women are generally poorer than other ethnic groups in the country and have limited access to adequate healthcare [12]. Moreover, previous cross-sectional studies conducted in South Africa [13-15] and other countries in the subSaharan African region [16, 17] have observed a positive association between higher body mass index (BMI) and improved SES. In addition, the contribution of SES and behaviours such as increased sitting time and physical inactivity on adiposity in high-income countries are well documented [18, 19], however evidence is limited on how these factors mediate and influence anthropometric changes in African populations. Therefore, the aims of this study were two-fold: (1) to determine whether SES correlates with anthropometry (both at baseline and at 10 year follow-up); and (2) to determine whether the interaction of SES with anthropometry is mediated by either moderate-vigorous physical activity (MVPA) or sitting time by using structural equation modelling (SEM).

\section{Methods}

\section{Participants and setting}

This longitudinal study included black South African urban-dwelling women from Soweto, Johannesburg [20]. These women were caregivers of participants from the Birth to Twenty Plus (Bt20) cohort, a study which started in 1990 with a sample of 3273 subjects [21, 22]. Women were enrolled in their second and third trimester of pregnancy through public health facilities and interviewed regarding their health and social history and current circumstances. Attrition over two decades has been comparatively low, mostly occurring during the children's infancy and early childhood [23]. The Bt20 sample is representative of families that have remained residents of Soweto for over 20 years, with equal numbers of male and female participants. Bt20 also monitors the health of the biological mothers or caregivers of the children and it is from these subjects that the study cohort was drawn. The baseline measurements for the current study were collected in 2002/3 on 1249 adult women (aged $\geq 18$ years), and the follow-up data collection wave was completed 10 years later (2012/13) on 702 women. This resulted in 518 women having body composition data at both time points, due to drop-out. Ethical approval was granted by the University of the Witwatersrand (Ethics certificate number: M110627) and all participants provided written consent.

\section{Biological variables}

Body weight $(\mathrm{kg})$ was measured to the nearest $0.1 \mathrm{~kg}$ using a digital weighing scale (Dismedinc., Anjou, Canada) and standing height was measured to the nearest $\mathrm{mm}$ using a wall stadiometer (Holtain Ltd., Crosswell, UK). The participants wore minimal clothing and did not have shoes on during the measurements. Trained research assistants conducted the measurements, and the coefficients of variation for body weight and standing height measurements were both $<1 \%$. Body mass index (BMI, $\mathrm{kg}^{-2} \mathrm{~m}^{-2}$ ) was calculated, and obesity was defined as BMI $\geq 30 \mathrm{~kg} \cdot \mathrm{m}^{-2}$ [24]. Using a flexible, but inelastic measuring tape, a measurement of the waist circumference was taken at the narrowest part of the trunk, horizontally, while the participants were standing with arms at the side, relaxed abdomen, and feet together [24]. The coefficients of variation for waist and hip circumference measurements were $<2 \%$. Central obesity was defined as waist circumference $\geq 80 \mathrm{~cm}$.

\section{Moderate-vigorous physical activity and sitting time}

Physical activity and sitting time was assessed using the interviewer-administered Global Physical Activity Questionnaire or GPAQ, developed for global physical activity surveillance [25]. Total moderate-vigorous physical activity (MVPA) minutes per week were calculated from the accumulative occupation-, travel-, and leisurerelated time physical activity. Sitting time (mins/wk) was used as a proxy for sedentary behaviour.

\section{Socioeconomic status and related variables}

A questionnaire was used to determine SES by using twelve household commodities to generate an SES index. The tool has been validated for use in South Africa by Griffiths et al. [26]. The use of asset indices have been acknowledged to the valuable proxy measures of SES in epidemiological studies [27]. The household indices used in this study included electricity, television, radio, motor vehicle, refrigerator, washing machine, telephone, video machine, microwave, analog television channel decoder (MNET), satellite television (DSTV), and mobile phone. These twelve household commodities were ranked in order of value and an overall SES score was then calculated using the ranks. The overall SES score ranged from 0 (ownership of no assets) to 78 (ownership of all 12 assets). The sample was split into 2 groups by SES median score, i.e. 30, and differences between these 2 groups were determined for all measured variables. Living arrangement was categorised and coded as: code 1 for 
'living together' (married or co-habiting), or code 2 for 'single' (divorced, separated, widowed, and not married). Highest level of education was collected at baseline and 10-year follow-up and coded as ' 1 ' for completion of primary school, ' 2 ' for incomplete high school, and ' 3 ' for completion of high school.

\section{Statistical analysis}

Continuous parametric data are presented as mean \pm SD or are displayed as median (interquartile range [IQR]) if their distribution was non-parametric. The physical activity measures, MVPA and sitting time were log transformed to normality. Data was compared between baseline and follow-up time points using Student's paired $\mathrm{t}$ test. Categorical, baseline data are presented as mean (95\% CIs). Student's non-paired $t$ test was used to compare baseline values for age, anthropometric and physical activity measures between groups with SES scores above or below the median value of 30 .

Structural equation modelling (SEM) was used to test and estimate the role of baseline SES (exogenous factor) on change in BMI, change in waist circumference, change in sitting time, and change in MVPA (endogenous factors). In the SEM model for change in BMI and change in MVPA, the potential mediators included baseline MVPA, change in MVPA (for change in BMI model only). Likewise, in the model for change in waist circumference and change in MVPA, baseline sitting time and change in sitting time (for the change in waist circumference model only) were the potential mediators. In the model for change in BMI and change in sitting time, baseline sitting and change in sitting time (only in the change in BMI model) were included as potential mediators. In the model for change in waist circumference and change in MVPA, baseline MVPA and change in MVPA (only in the change in waist circumference model) were included as potential mediators. Age was treated as a confounding variable in all the SEM models. Univariate analysis, using Spearman Rank Order correlations, were conducted to determine the association of SEM parameters with the dependent variables. Direct, indirect and total effects were computed and recoded, and the proportion of total effects mediated was calculated for assessing mediation roles. Different goodness of fit indices was used to evaluate the best fitting model. Chi-squared test, Root mean squared error of approximation (RMSEA), Comparative fit index (CFI), Tucker-Lewis index (TLI) and Standardized root mean squared residual (SRMR) were calculated and recorded [28]. We employed the $\mathrm{Hu}$ and Bentler's Two-Index Presentation Strategy (1999) combination rule with cut off values for CFI $(\geq 0.90)$, SRMR $(\leq 0.09)$, RMSEA $(\leq 0.06)$ included for best fit [28].

\section{Results}

\section{Study population}

Table 1 displays the study population's baseline and 10year follow-up characteristics. Mean age at baseline was $41.1 \pm 5.8$ years and at follow-up age was $49.3 \pm 5.3$ years. BMI increased significantly from $31 \pm 6.7 \mathrm{~kg} . \mathrm{m}^{-2}$ at baseline to $33.3 \pm 7.4 \mathrm{~kg} . \mathrm{m}^{-2}$ at follow-up $(p<0.0001)$, while waist circumference similarly increased from $88 \pm 13.3$ at baseline to $98.9 \pm 14.6$ at follow-up $(p<0.0001)$. Obesity $\left(\mathrm{BMI} \geq 30 \mathrm{~kg} \cdot \mathrm{m}^{-2}\right)$ and central obesity increased significantly from baseline to 10 -year follow-up $(p<0.0001)$. Sitting time decreased significantly from baseline to followup $(p<0.0001)$. Women in the lower SES group were older $(41.7 \pm 7.83$ vs $40.7 \pm 8.01$, respectively, $p=0.04)$ and had a lower change in BMI compared with women above the median for SES $(1.80 \pm 3.59$ vs $2.94 \pm 3.90$, respectively, $p=0.001)$. No other differences between the two SES groups were observed. Sensitivity tests of the baseline study characteristics were conducted to check for selection and attrition bias. As shown in Additional file 1, there were no significant differences between those at baseline and at 10-year follow-up using the baseline study characteristics. Just under half of the sample were living together, $46.7(43.7 ; 49.4)$, while the mean SES score was $32.7 \pm 16.8$.

At baseline $12.5 \%(9.94,13.6 \%)$ attended primary school, $70.3 \%(67.7,72.8 \%)$ did not complete high school, and only $17.2 \%(15.2,19.4 \%)$ completed high school. The 10-year, follow-up data showed that there was an increase in the amount of women who completed high school $(p<0.0001)(12.5 \%(10.7,14.5 \%)$ completed primary school, $57.0 \%(52.8,61.1 \%)$ did not complete high school, and $30.7 \%(27.0,34.7 \%)$ completed high school). The women who completed high school were younger than those who only completed school at an elementary level $(40.3 \pm 6.79$ vs $46.4 \pm 7.86$ years; $p<0.0005)$. There were no other differences between the education status groups for body composition or physical activity indicators at baseline or absolute change.

In a univariate analysis of the parameters used in the SEM models, there was a positive correlation between baseline SES and change in BMI $(r=0.13, p=0.002)$, and a negative correlation between age and change in BMI $(r=-0.14, p=0.001)$ (see Table 2). Change in waist was negatively correlated with baseline waist $(r=-0.19$, $p<0.0001)$ and age $(r=-0.09, p=0.03)$. Change in MVPA was negatively correlated with baseline MVPA $(r=-0.68, p<0.0001)$, and baseline sitting time $(r=-0.12$, $p=0.01$ ), while positively correlated with change in sitting time $(r=0.13,0.006)$. Changes in sitting time was positively correlated with baseline sitting time $(r=0.92, p<0.0001)$, while negatively correlated with baseline MVPA $(r=-0.14, p=0.005)$. 
Table 1 Sample characteristics of urbanised black South African women living in Soweto

\begin{tabular}{|c|c|c|c|c|}
\hline & Baseline & Follow-up & Net change & $p$-value \\
\hline Age (years) & $41.4 \pm 5.8$ & $49.3 \pm 5.3$ & +7.9 & $<0.0001$ \\
\hline Height (m) & $1.58 \pm 0.05$ & - & - & - \\
\hline Weight (kg) & $76.1 \pm 15.1$ & $80.5 \pm 16.3$ & +4.4 & $<0.0001$ \\
\hline BMI $\left(\mathrm{kg} \cdot \mathrm{m}^{-2}\right)$ & $31 \pm 6.7$ & $33.3 \pm 7.4$ & +2.3 & $<0.0001$ \\
\hline $\mathrm{BMI} \geq 30 \mathrm{~kg} \cdot \mathrm{m}^{-2}, \%$ & $52.2(48.1,56.4)$ & $67.4(63.4,71.2)$ & +15.2 & $<0.0001$ \\
\hline$W C(\mathrm{~cm})$ & $88 \pm 13.3$ & $98.9 \pm 14.6$ & +10.9 & $<0.0001$ \\
\hline Central obesity, WC $\geq 80 \mathrm{~cm}, \%$ & $72(68,75.6)$ & $90(87.2,92.2)$ & +18 & $<0.0001$ \\
\hline MVPA (mins./week) & $350(150,1230)$ & $240(60,1035)$ & -110 & 0.57 \\
\hline Sitting time (mins./week) & $1260(840,2100)$ & $690(510,915)$ & -570 & $<0.0001$ \\
\hline
\end{tabular}

Data presented as mean \pm SD or percentage (\%) $(95 \% \mathrm{Cls})$ or median (interquartile range); + increase; - decrease

$B M I$ body mass index; MVPA moderate-vigorous physical activity; WC waist circumference; Paired t-tests were used to describe the difference in baseline and follow-up values

\section{Structural equation modelling}

The SEM models for changes in BMI, changes in WC, and changes in physical activity measures and the interaction with baseline SES are shown in Table 3. Baseline SES had a direct positive effect on change in BMI and a direct negative effect on change in MVPA $(p<0.05)$. Baseline SES had a direct negative effect (via baseline WC) on change in MVPA $(p<0.05)$. Baseline MVPA had an indirect negative effect (via change in MVPA) on change in BMI, and an indirect negative effect on change in WC (via change in MVPA). Baseline MVPA had a direct negative effect on change in WC $(p<0.05)$, and a direct negative effect on change in MVPA $(p<0.0001)$. Baseline sitting time had an indirect negative effect (via change in sitting time) on change in BMI and change in WC $(p<0.0001)$, while having a direct negative effect on change in sitting time $(p<0.0001)$. Baseline WC had a direct negative effect on change in WC $(p<0.0001)$. Finally, change in MVPA had a direct negative effect on change in WC.
The values indicated that the model was acceptable and best fit for the model (Table 4, Fig. 1). The SEM model for SES and baseline MVPA on change in BMI resulted in a model with a CFI value of 1.00, RMSEA value of 0.000 , and SRMR value of 0.01 (Table 4, Fig. 1a). Table 4 and Fig. $1 \mathrm{~b}$ represent the SEM model for the association of baselines SES and sitting on change in BMI. The CFI (1.00), RMSEA (0.000), and SRMR (0.01) indicated a good fit for the SEM model. The SEM for SES and baseline MVPA on change in waist is shown in Table 4 and Fig. 1c, and is considered to be the best fit model $(C F I=1.00 ; \quad R M S E A=0.000 ; \quad S R M R=0.01)$. The SEM model for baseline SES and baseline sitting on change in WC likewise presented a good fit with $\mathrm{CFI}=1.00$; RMSEA $=0.000$; and SRMR $=0.01$ (Table 4 and Fig. $1 \mathrm{~d}$ ).

\section{Discussion}

The purpose of this longitudinal study was to determine the extent to which physical activity or sitting time mediate the association between SES and changes in

Table 2 Correlation between physical activity, socioeconomic status parameters and endogenous factors used in the structural equation modelling

\begin{tabular}{lllll}
\hline Parameter & BMI $^{\mathrm{b}}$ & WC $^{\mathrm{b}}$ & MVPA $^{\mathrm{b}}$ & Sitting time $^{\mathrm{b}}$ \\
\hline Age $^{\mathrm{a}}$ & $-0.14(0.001)$ & $-0.09(0.03)$ & $-0.01(0.82)$ & $0.02(0.67)$ \\
BMI $^{\mathrm{a}}$ & $-0.07(0.12)$ & - & $-0.02(0.78)$ & $0.06(0.62)$ \\
WC $^{\mathrm{a}}$ & - & $-0.19(<0.0001)$ & $-0.02(0.61)$ & $0.04(0.46)$ \\
MVPA $^{\mathrm{a}}$ & $-0.03(0.54)$ & $-0.01(0.14)$ & $-0.68(<0.0001)$ & $-0.14(0.005)$ \\
MVPA $^{\mathrm{b}}$ & $-0.03(0.54)$ & $-0.01(0.76)$ & - & $0.13(0.006)$ \\
Sitting time $^{\mathrm{a}}$ & $0.02(0.64)$ & $0.07(0.16)$ & $-0.12(0.01)$ & $0.92(<0.0001)$ \\
Sitting time $^{\mathrm{b}}$ & $-0.01(0.76)$ & $-0.06(0.25)$ & $0.13(0.006)$ & - \\
SES score $^{\mathrm{a}}$ & $0.13(0.002)$ & $0.08(0.07)$ & $-0.08(0.09)$ & $0.04(0.47)$ \\
\hline
\end{tabular}

Data are presented as $\mathrm{r}$ ( $p$-value)

BMI body mass index; MVPA moderate-vigorous physical activity; SES socioeconomic status; WC waist circumference

a Baseline values

${ }^{\mathrm{b}}$ Change values 
Table 3 Structural equation models for the relationship between socioeconomic status, MVPA, and sitting time on changes in BMI and WC in urban black South African women

\begin{tabular}{|c|c|c|c|c|c|}
\hline Effect of: & Outcomes: & Direct effects & Indirect effects & Total effects & $\begin{array}{l}\text { Proportion of total } \\
\text { effect mediated }\end{array}$ \\
\hline \multirow[t]{3}{*}{$\overline{\mathrm{SES}^{\mathrm{b}}}$} & $\mathrm{BMI}^{\mathrm{c}}$ via $\mathrm{MVPA}^{\mathrm{b}}$ & $0.022(0.003 ; 0.041)^{*}$ & $0.0006(-0.0022 ; 0.0035)$ & $0.0226(0.0038 ; 0.0413)^{*}$ & 0.03 \\
\hline & $\mathrm{MVPA}^{\mathrm{c}}$ via $\mathrm{BM} \mathrm{I}^{\mathrm{b}}$ & $-3.81(-6.92 ;-0.70)^{*}$ & $-0.39(-4.84 ; 4.06)$ & $-4.20(-9.63 ; 1.22)$ & 0.1 \\
\hline & Sitting ${ }^{c}$ via $W C^{b}$ & $1.08(-0.83 ; 2.98)$ & $0.07(-4.73 ; 4.86)^{*}$ & $1.14(-4.02 ; 6.30)$ & 0.06 \\
\hline \multirow[t]{4}{*}{ MVPA $^{\mathrm{b}}$} & $\mathrm{BMI}^{\mathrm{c}}$ via MVPA ${ }^{c}$ & $-0.0004(-.001 ; 0.000)$ & $0.0003(0.0003 ; 0.0003)^{* * *}$ & $-0.0001(-0.0007 ; 0.0004)$ & $0.43^{\mathrm{a}}$ \\
\hline & $W C^{c}$ via $M V P A^{c}$ & $-0.002(-0.003 ;-0.0003)^{*}$ & $0.01(0.001 ; 0.001)^{* * *}$ & $-0.001(-0.002 ; 0.001)$ & $10^{\mathrm{a}}$ \\
\hline & $\mathrm{MVPA}^{\mathrm{c}}$ via $\mathrm{BMI}^{\mathrm{b}}$ & $-0.87(-0.92 ;-0.82)^{* * *}$ & $-0.0003(-0.0009 ; 0.0004)$ & $-0.87(-0.92 ;-0.82)^{* * *}$ & 0.0003 \\
\hline & $\mathrm{MVPA}^{\mathrm{c}}$ via $W C^{\mathrm{b}}$ & $-0.87(-0.92 ;-0.82)^{* * *}$ & $-0.0008(-0.004 ; 0.002)$ & $-0.87(-0.92 ;-0.82)^{* * *}$ & $0.001^{\mathrm{a}}$ \\
\hline \multirow[t]{3}{*}{ Sitting $^{b}$} & $\begin{array}{l}\text { BMI }^{c} \\
\text { via Sitting }^{c}\end{array}$ & $-0.0002(-0.0009 ; 0.001)$ & $0.0001(0.0001 ; 0.0002)^{* * *}$ & $-0.00002(-0.0008 ; 0.001)$ & $5.00^{\mathrm{a}}$ \\
\hline & $W^{c} v^{c}$ ia Sitting ${ }^{c}$ & $-0.0004(-0.002 ; 0.001)$ & $0.0006(0.0005 ; 0.001)^{* * *}$ & $0.0002(-0.002 ; 0.002)$ & 3.00 \\
\hline & Sitting ${ }^{c}$ via $W C^{b}$ & $-0.84(-0.86 ;-0.81)^{* * *}$ & $0.0004(-0.0005 ; 0.001)$ & $-0.84(-0.86 ; 0.81)^{* * *}$ & $0.001^{\mathrm{a}}$ \\
\hline \multirow[t]{2}{*}{$W C^{b}$} & $\begin{array}{l}\text { WC } \\
\text { via MVPAc }\end{array}$ & $-0.12(-0.18 ;-0.05)^{* * *}$ & $0.003(-0.002 ; 0.09)$ & $-2.45(-6.56 ; 1.67)$ & $0.001^{\mathrm{a}}$ \\
\hline & $W^{c}{ }^{c}$ via Sitting ${ }^{c}$ & $-0.11(-0.17 ;-0.05)^{* * *}$ & $0.0006(-0.001 ; 0.002)$ & $-0.11(-0.17 ;-0.05)^{* * *}$ & $0.01^{\mathrm{a}}$ \\
\hline MVPA $^{c}$ & $W C^{c}$ & $-0.001(-0.003 ;-0.00004)^{*}$ & & $-0.001(-0.003 ;-0.00004)^{*}$ & \\
\hline
\end{tabular}

Data in parentheses are $95 \% \mathrm{Cls}$; All models were adjusted for age

MVPA moderate to vigorous physical activity, $B M I$ body mass index, SES socioeconomic status, WC waist circumference

${ }^{*} P<0.05 ;{ }^{* * *} P<0.001$

${ }^{a}$ Assessed using the absolute values for both indirect and direct effects

baseline values

${ }^{c}$ Change values

BMI and central adiposity. The obesity trends observed in this study population are consistent with changes in adiposity in African women living in other sub-Saharan African countries [4]. This study confirms previous reports of increases in adiposity over time in African women, and shows how household asset derived SES influences these changes. We have shown that SES is associated with lower MVPA, higher sitting time, and consequently higher changes in BMI, suggesting that this cohort of African women is still experiencing some degree of economic transition. The results demonstrating the direct and indirect effects of SES and physical activity measures on changes in adiposity are the first from an African study, and could only be uncovered using structural equation modelling. Public health initiatives should be made aware of these study findings, particularly as obesity continues to increase with economic improvement in the sub-Saharan African region.
Research from South Africa [13-15] and other subSaharan African countries $[16,17]$ have shown that SES is positively associated with BMI. A country-wide demographic study in South Africa also showed that in all ethnic groups, men and women with some form of schooling have higher BMI values than those who have not attended school [29]. The findings of the present study confirm the current evidence, suggesting that adiposity increases with economic growth. In contrast, existing work from high-income countries shows that SES is inversely related with health outcomes [30, 31], while in non-African developing countries the relationship between SES and BMI does not appear to be constant [32]. In a recent study of young adult black South African women, SES was observed to have a direct effect on BMI in the urban population but not in the rural population [33]. These data support the phenomenon of within-country variation in the impact of SES on body

Table 4 Fit indices for the structural equation model

\begin{tabular}{|c|c|c|c|c|c|c|c|}
\hline Model & $x^{2}$ & Prob $>X^{2}$ & RMSEA & $\mathrm{CFI}$ & TLI & SRMR & $C D$ \\
\hline$\overline{\text { SES } \text { and MVPA on BMl }}$ & 1.77 & 0.88 & 0.00 & 1.00 & 1.01 & 0.006 & 0.06 \\
\hline SES and sitting time on $\mathrm{BMI}^{\mathrm{a}}$ & 3.57 & 0.61 & 0.00 & 1.00 & 1.00 & 0.006 & 0.05 \\
\hline SES and MVPA on WC ${ }^{a}$ & 1.02 & 0.91 & 0.00 & 1.00 & 1.02 & 0.005 & 0.04 \\
\hline SES and sitting time on $\mathrm{WC}^{\mathrm{a}}$ & 3.16 & 0.53 & 0.00 & 1.00 & 1.00 & 0.006 & 0.03 \\
\hline
\end{tabular}

RMSEA Root Mean Square Error of Approximation, CFI Comparative Fit Index, TLI Tucker Lewis Index, SRMR Standardized Root Mean Squared Residual, $C D$ Coefficient of Determination, BMI body mass index, WC waist circumference, SES socioeconomic status

${ }^{a}$ Change values; $X^{2}=$ Chi-squared test of fit model 

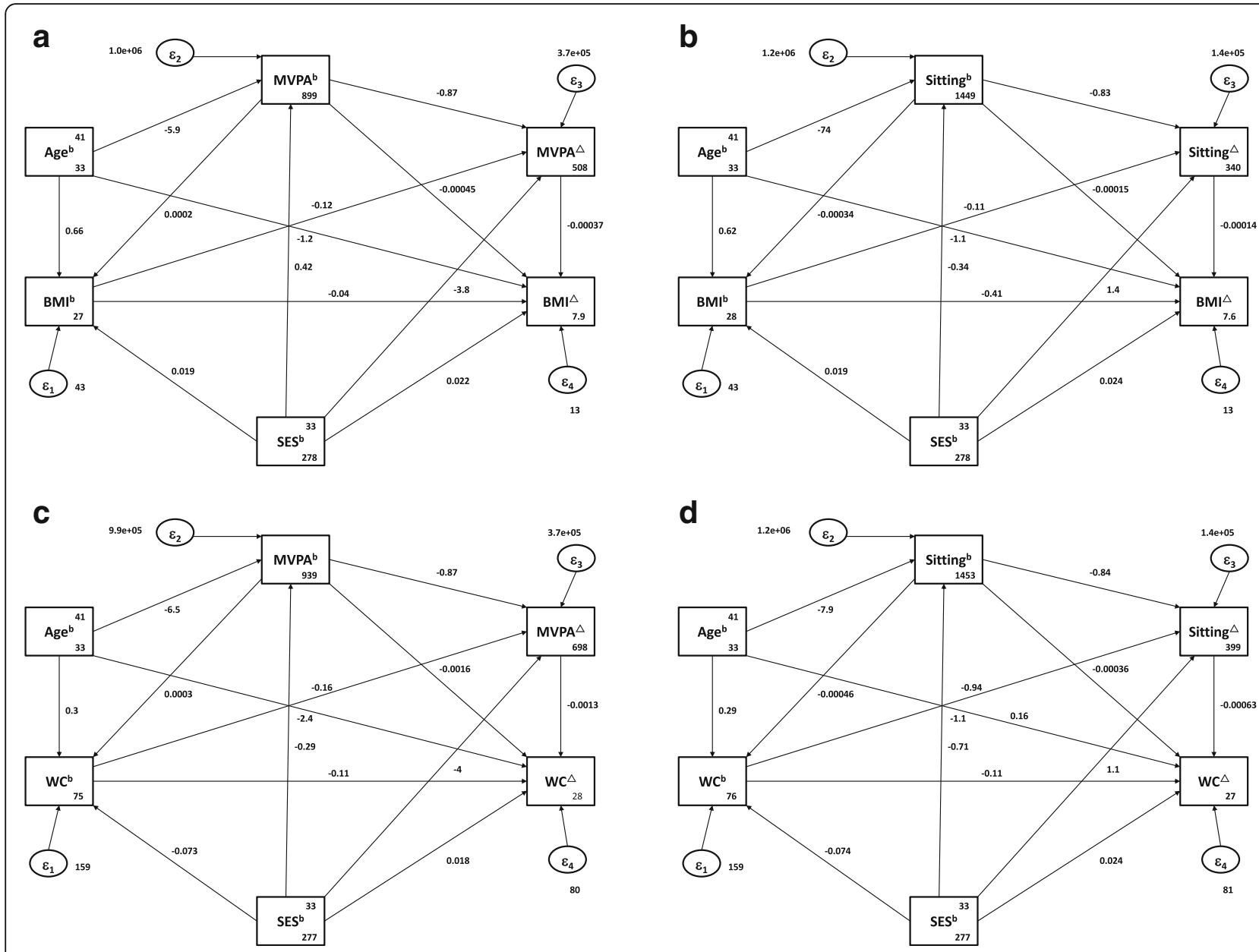

Fig. $1 \mathbf{a}, \mathbf{b}, \mathbf{c}$ and $\mathbf{d}$ : Path diagram of the association of socioeconomic status (SES) with change in body mass index (BMI) via baseline (b) and change $\left(^{(}\right)$in moderate-vigorous physical activity (MVPA) $(\mathbf{a})$ and via sitting time ${ }^{\mathrm{b} \Delta}(\mathbf{b})$; and the association of baseline SES with change in waist circumference (WC) via MVPA ${ }^{\mathrm{b} \Delta}$ (c) and sitting time ${ }^{\mathrm{b} \Delta}$ (d)

adiposity, and can further vary according to regionspecific sociodemographic context and geographic location [34]. Given the well-known nutritional and epidemiological transitions currently occurring in South Africa [35], our finding showing that SES was associated with lower change in MVPA is not surprising and is consistent with evidence from cross sectional $[19,33]$ and longitudinal studies [36, 37]. In rural South African populations, SES is positively associated with physical activity in adolescents [38] but not in adult women [33]. The urban-rural variation in socioeconomic status could explain the reason for the lack of association between SES and physical activity in rural dwelling women [33].

Consistent with other studies of African women, our data shows that urban dwelling African women have a high level of physical activity [38-40]. These studies show that rural dwelling African women have higher amounts of MVPA compared with urban dwellers. The transition to urban hubs results in acquiring comparatively less energy-demanding jobs than in the rural settings [41], and this may be another reason for the greater difference in volume of physical activity observed in urban African women [33]. Women in urban settings sit for longer periods as a consequence of less physically demanding work, and this could explain the indirect positive effect between baseline sitting and change in BMI and central fat demonstrated in the present study. Interestingly, these effects were mediated by greater increases in sitting time. Previous studies of the cohort in the present study have shown that high sitting is associated with obesity and associated cardiometabolic diseases [42]. The literature indicates an increasing pattern of obesity with continuing urbanisation in African populations [4]. Public health interventions can address the problem by targeting sedentary behaviour, particularly during travel and occupation time. The recent work by Ekelund et al. for example [18], demonstrates that reduced sitting time is associated with lower risk for all-cause mortality by improving cardiovascular health. 
Baseline MVPA was shown to have a direct negative effect on change in central fat, which is consistent with other studies [43], and suggests that physical activity has a protective effect against excess fat accumulation. Our findings also reveals an indirect positive effect between baseline MVPA and measures of change in adiposity, driven by the direct negative effect between baseline MVPA and change in MVPA. This suggests that change in MVPA may a potential confounder as this study population ages, possibly explained by the continuous rural-urban shift as noted in a recent of younger adult African women [33]. We agree with this explanation, however the literature also suggests that eating behaviour and other potential correlates of obesity can change during the transition period [32], emphasising the need for additional investigation of behaviour in the current study population. Further, evidence demonstrates that in spite of transitioning populations obtaining sufficient levels of weekly physical activity, obesity levels continue to increase [44]. In the current study, the prevalence of obesity and central fat increased significantly in the study population from baseline to 10-year follow-up, by $15.2 \%$ and $18 \%$ respectively, however, the weekly MVPA was high, 50 mins./day at baseline and $34.3 \mathrm{mins}$./day at follow-up. In the context of a growing population of ageing African women, it is therefore paramount for policy makers to consider incorporating other forms of behavioural modification such as lowering caloric consumption to decrease weight gain.

The SEM approach used in this study has a number of strengths, particularly in understanding the increasing risk of obesity in African women. SEM has been used widely in cross-sectional and longitudinal studies, and despite being seldom used in epidemiological research this approach has applications in path analysis [45]. Sample size is the main limitation related to the SEM approach, and as evidence recommends a minimum of 200 observations, this was not a concern [46]. In this longitudinal study, SEM enabled the measurement of direct, indirect, and total effects, in addition to interpreting the underlying pathways of increasing body composition by detecting or removing the possible mediators involved in the accumulation of fat in women over a 10-year followup period. In this study we have therefore observed novel and scientifically plausible pathways which previous traditional multivariable regression analyses of this study population have not uncovered [20]. In addition, this study has highlighted the direct and indirect effects in the relationship between SES and physical activity determinants of change in adiposity in African women [20, 42].

The main limitation of this study was that measurements were made only at baseline and 10 years later due to limited resources, however the 10-year follow-up period did allow us to observe the long term influence of baseline determinants and changes in appropriate variables on body anthropometry in an African population with high obesity risk. This study did not control for eating behaviour as data were not available, however this data are currently being collected with the aim of understanding the role of caloric intake in obesity in African women. In addition, future studies should collect data on other potential behavioural predictors of adiposity. The physical activity measures obtained in the present study are based on the self-reported and validated global physical activity questionnaire [25]. Despite the methodological differences, our findings are similar to studies using objectively measured physical activity [43]. Better methods such as MRI can provide more definitive data on adiposity compared with BMI, however, it is still acknowledged to be one of the simplest proxy indicators of fat and is widely used in epidemiological studies $[4,5]$.

\section{Conclusions}

In conclusion, this study demonstrates that the physical activity profile of urban African women is reasonable; however the threat of obesity is high and likely to continue increasing with advancing age. Changes in BMI and central fat can be minimised by maintaining or increasing energy expenditure through physical activity, in addition to limiting the negative impact of sedentary behaviour. The influence of other behavioural determinants should however also be considered in any future initiatives to address obesity in this vulnerable community of ageing African women.

\section{Additional file}

Additional file 1: Sensitivity analysis on baseline study characteristics for participants in and out of the study. (DOCX $16 \mathrm{~kb}$ )

\section{Acknowledgements}

This work is based on the research supported in part by the National Research Foundation of South Africa (NRF) for the Grant No.: 113366. Any opinion, finding and conclusion or recommendation expressed in this material is that of the author(s) and the NRF does not accept any liability in this regard.

Funding

Bt20 is supported by funding from the University of the Witwatersrand, South African Medical Research Council and the DST-NRF Centre of Excellence in Human Development.

Availability of data and materials

Given ethical constraints and protection of participants' information, the sharing of data used in this study cannot be made publicly available.

Authors' contributions

PJG and RM performed the statistical analyses, and interpreted the data. PJG implemented the study and wrote the paper. All authors conceived the experiments, read and commented on the paper, and approved the final version of the manuscript. 


\section{Ethics approval and consent to participate}

Ethical approval was granted by the University of the Witwatersrand (Ethics certificate number: M110627) and all participants provided written consent.

\section{Competing interests}

The authors declare that they have no competing interests.

\section{Publisher's Note}

Springer Nature remains neutral with regard to jurisdictional claims in published maps and institutional affiliations.

\section{Author details}

${ }^{1}$ Centre for Exercise Science and Sports Medicine, Faculty of Health Sciences, University of the Witwatersrand, Johannesburg, South Africa. ${ }^{2} \mathrm{MRC}$ Wits Developmental Pathways for Health Research Unit, Faculty of Health Sciences, University of the Witwatersrand, Johannesburg, South Africa. ${ }^{3}$ Department of Chemical Pathology, National Health Laboratory Service, Faculty of Health Sciences, University of the Witwatersrand, Johannesburg, South Africa.

\section{Received: 24 October 2017 Accepted: 20 April 2018}

\section{Published online: 26 April 2018}

\section{References}

1. Swinburn BA, Sacks G, Hall KD, McPherson K, Finegood DT, Moodie ML, Gortmaker SL. The global obesity pandemic: shaped by global drivers and local environments. Lancet. 2011;378:804-14.

2. Gwatkin DR. Health inequalities and the health of the poor: what do we know? What can we do? Bull World Health Organ. 2000;78:3-18.

3. GBD 2015 Obesity Collaborators. Health effects of overweight and obesity in 195 countries over 25 years. N Engl J Med. 2017;377(1):13-27.

4. NCD Risk Factor Collaboration (NCD-RisC) - Africa Working Group. Trends in obesity and diabetes across Africa from 1980 to 2014: an analysis of pooled population-based studies. Int J Epidemiol. 2017;46:1421-32.

5. NCD Risk Factor Collaboration (NCD-RisC). Trends in adult body-mass index in 200 countries from 1975 to 2014: a pooled analysis of 1698 populationbased measurement studies with 19.2 million participants. Lancet. 2016:387:1377-96.

6. Dixon JB. The effect of obesity on health outcomes. Mol Cell Endocrinol. 2010;316:104-8.

7. Preston SH, Stokes A. Contribution of obesity to international differences in life expectancy. Am J Public Health. 2011;101:2137-43.

8. Corica F, Bianchi G, Corsonello A, Mazzella N, Lattanzio F, Marchesini G. Obesity in the context of aging: quality of life considerations. PharmacoEconomics. 2015;33:655-72.

9. Ng M, Fleming T, Robinson M, Thomson B, Graetz N, Margono C, Mullany EC, Biryukov S, Abbafati C, Abera SF, et al. Global, regional, and national prevalence of overweight and obesity in children and adults during 1980-2013: a systematic analysis for the global burden of disease study 2013. Lancet. 2014;384:766-81.

10. Gabriely I, Ma XH, Yang XM, Atzmon G, Rajala MW, Berg AH, Scherer P, Rossetti L, Barzilai N. Removal of visceral fat prevents insulin resistance and glucose intolerance of aging: an adipokine-mediated process? Diabetes. 2002:51:2951-8.

11. Westerterp KR. Daily physical activity as determined by age, body mass and energy balance. Eur J Appl Physiol. 2015;115:1177-84.

12. Poverty trends in South Africa: an examination of absolute poverty between 2006 and 2011. Pretoria: Statistics South Africa. 2014. http://beta2.statssa. gov.za/publications/Report-03-10-06/Report-03-10-06March2014.pdf.

13. Puoane T, Steyn K, Bradshaw D, Laubscher R, Fourie J, Lambert V, Mbananga N. Obesity in South Africa: the south African demographic and health survey. Obes Res. 2002;10:1038-48.

14. Kruger HS, Venter $\mathrm{CS}$, Vorster HH. Obesity in African women in the north West Province, South Africa is associated with an increased risk of non-communicable diseases: the THUSA study. Transition and health during urbanisation of south Africans. Brit J Nutr. 2001;86:733-40.

15. Mfenyana K, Griffin M, Yogeswaran P, Modell B, Modell M, Chandia J, Nazareth I. Socio-economic inequalities as a predictor of health in South Africa-the Yenza cross-sectional study. S Afr Med J. 2006;96:323-30.

16. Letamo G. The prevalence of, and factors associated with, overweight and obesity in Botswana. J Biosoc Sci. 2011;43:75-84.
17. Steyn NP, Nel JH, Parker WA, Ayah R, Mbithe D. Dietary, social, and environmental determinants of obesity in Kenyan women. Scand J Public Health. 2011;39:88-97.

18. Ekelund U, Steene-Johannessen J, Brown WJ, Fagerland MW, Owen N Powell KE, Bauman A, Lee IM, Committe; LPASE, Group LSBW. Does physical activity attenuate, or even eliminate, the detrimental association of sitting time with mortality? A harmonised meta-analysis of data from more than 1 million men and women. Lancet. 2016;388:1302-10.

19. Shoham DA, Dugas LR, Bovet P, Forrester TE, Lambert EV, Plange-Rhule J, Schoeller DA, Brage S, Ekelund U, Durazo-Arvizu RA, et al. Association of car ownership and physical activity across the spectrum of human development: modeling the epidemiologic transition study (METS). BMC Public Health. 2015;15:173.

20. Gradidge PJ, Norris SA, Micklesfield LK, Crowther NJ. The role of lifestyle and psycho-social factors in predicting changes in body composition in black south African women. PLoS One. 2015;10:e0132914.

21. Richter LM, Norris SA, De Wet T. Transition from birth to ten to birth to twenty: the south African cohort reaches 12 years of age. Paediatr Perinat Epidemiol. 2004;18:290-301.

22. Crowther NJ, Norris SA. The current waist circumference cut point used for the diagnosis of metabolic syndrome in sub-Saharan African women is not appropriate. PLoS One. 2012;7:e48883.

23. Norris SA, Richter LM, Fleetwood SA. Panel studies in developing countries: case analysis of sample attrition over the past 15 years within the birth to twenty cohort in Johannesburg, South Africa. J Int Dev. 2007;19:1143-50.

24. American College of Sports Medicine. ACSM's Guidelines for Exercise Testing and Prescription, 10th Edition. Philadelphia: Wolters Kluwer/ Lippincott Williams \& Wilkins; 2017.

25. Bull FC, Maslin TS, Armstrong T. Global physical activity questionnaire (GPAQ): nine country reliability and validity study. J Phys Act Health. 2009;6:790-804.

26. Griffiths PL, Rousham EK, Norris SA, Pettifor JM, Cameron N. Socio-economic status and body composition outcomes in urban south African children. Arch Dis Child. 2008;93:862-7.

27. Filmer D, Scott K. Assessing asset indices. Demography. 2012;49:359-92.

28. Hu L, Bentler PM. Cutoff criteria for fit indexes in covariance structure analysis: conventional criteria versus new alternatives. Struct Equ Modeling. 1999;6:1-55.

29. Department of Health, Medical Research Council, OrcMacro. South Africa demographic and health survey 2003. Pretoria: Department of Health; 2007.

30. Myer L, Stein D, Grimsrud A, Seedat S, Williams D. Social determinants of psychological distress in a nationally-representative sample of south African adults. Soc Sci Med. 2008;66:1828-40.

31. Mackenbach J. Socio-economic health differences in the Netherlands: a review of recent empirical findings. Soc Sci Med. 1992;34:213-26.

32. Monteiro CA, Moura EC, Conde WL, Popkin BM. Socioeconomic status and obesity in adult populations of developing countries: a review. Bull World Health Organ. 2004;82:940-6.

33. Micklesfield LK, Munthali RJ, Prioreschi A, Said-Mohamed R, van Heerden A, Tollman S, Kahn K, Dunger D, Norris SA. Understanding the relationship between socio-economic status, physical activity and sedentary behaviour, and adiposity in young adult south African women using structural equation modelling. Int J Environ Res Public Health. 2017;14.

34. Lebel A, Kestens Y, Clary C, Bisset S, Subramanian SV. Geographic variability in the association between socioeconomic status and BMI in the USA and Canada. PLoS One. 2014;9:e99158.

35. Abrahams Z, McHiza Z, Steyn NP. Diet and mortality rates in sub-Saharan Africa: stages in the nutrition transition. BMC Public Health. 2011;11:801.

36. Turrell G, Hewitt B, Haynes M, Nathan A, Giles-Corti B. Change in walking for transport: a longitudinal study of the influence of neighbourhood disadvantage and individual-level socioeconomic position in mid-aged adults. Int J Behav Nutr Phys Act. 2014;11:151.

37. Sanchez A, Grandes G, Ortega Sánchez-Pinilla R, Torcal J, Montoya I, PEPAF Group. Predictors of long-term change of a physical activity promotion programme in primary care. BMC Public Health. 2014;14:108.

38. Micklesfield LK, Pedro TM, Kahn K, Kinsman J, Pettifor JM, Tollman S, Norris SA. Physical activity and sedentary behavior among adolescents in rural South Africa: levels, patterns and correlates. BMC Public Health. 2014;14:40.

39. Guthold R, Ono T, Strong KL, Chatterji S, Morabia A. Worldwide variability in physical inactivity a 51-country survey. Am J Prev Med. 2008;34:486-94.

40. Assah FK, Ekelund U, Brage S, Mbanya JC, Wareham NJ. Urbanization, physical activity, and metabolic health in sub-Saharan Africa. Diabetes Care. 2011;34:491-6. 
41. Lambert EV. Physical activity as a global risk factor for non-communicable diseases: time for action, what, why, when, who and how? S Afr J SM. 2012;24:25-6.

42. Gradidge PJ, Crowther NJ, Chirwa ED, Norris SA, Micklesfield LK. Patterns, levels and correlates of self-reported physical activity in urban Soweto women. BMC Public Health. 2014;14:934.

43. Ekelund U, Kolle E, Steene-Johannessen J, Dalene KE, Nilsen AKO, Anderssen SA, Hansen BH. Objectively measured sedentary time and physical activity and associations with body weight gain: does body weight determine a decline in moderate and vigorous intensity physical activity? Int J Obes. 2017:41:1769-74

44. Dugas LR, Kliethermes S, Plange-Rhule J, Tong L, Bovet P, Forrester TE, Lambert EV, Schoeller DA, Durazo-Arvizu RA, Shoham DA, et al. Accelerometer-measured physical activity is not associated with two-year weight change in African-origin adults from five diverse populations. PeerJ. 2017;5:e2902.

45. Day NE, Wong MY, Bingham S, Khaw KT, Luben R, Michels KB, Welch A, Wareham NJ. Correlated measurement error-implications for nutritional epidemiology. Int J Epidemiol. 2004;33:1373-81.

46. Tomarken AJ, Waller NG. Structural equation modeling: strengths, limitations, and misconceptions. Annu Rev Clin Psychol. 2005;1:31-65.

Ready to submit your research? Choose BMC and benefit from:

- fast, convenient online submission

- thorough peer review by experienced researchers in your field

- rapid publication on acceptance

- support for research data, including large and complex data types

- gold Open Access which fosters wider collaboration and increased citations

- maximum visibility for your research: over $100 \mathrm{M}$ website views per year

At BMC, research is always in progress.

Learn more biomedcentral.com/submissions 